\title{
Research on the Development Status and Strategies of Tourism E-commerce in Fuzhou City
}

\author{
Man Huang ${ }^{\mathrm{a}, *}$, Qingguo Tang \\ School of Economics and Management, Nanjing University of Science and Technology, Nanjing \\ 210094, China \\ a1577464836@qq.com, ${ }^{b}$ tangqguo@163.com \\ * Man Huang
}

Keywords: Fuzhou tourism; Tourism e-commerce; Market analysis; Development strategy.

\begin{abstract}
Fuzhou, located in the eastern Jiangxi Province, has a calm river, Xinjiang, with the three drainage in the east, south and west sides surrounded by mountains. It is a mountain with rich tourism resources, and how to fully apply e-commerce to Fuzhou tourism is facing opportunities and challenges. In this paper, mainly from the background, significance, status quo analysis, objectives, strategies, etc., present situation and the potential market of Fuzhou tourism e-commerce development is analyzed, so as to promote Fuzhou tourism industrial structure adjustment, to further promote the development of Fuzhou tourism e-commerce. With the reference to related tourism electronic commerce in other provinces and cities, the advantages of Fuzhou tourism combining its own characteristics are analyzed, and the corresponding tourism electronic commerce development strategy is put forward.
\end{abstract}

\section{Introduction}

Fuzhou city has a long history and rich tourism resources, but because of the relatively backward in economy in Jiangxi province and its scenic spot propaganda is insufficient, which leads to the serious information asymmetry problems with the outside world, the tourism electronic commerce can let visitors effective understanding of the scenic spot of information thus increasing demand for tourists to mobilize. Nowadays the development of Fuzhou city tourism electricity is still unsatisfactory, major development opportunities still need to hold, so we should focus on analysis of electricity deficiency of Fuzhou city tourism, mining and seize the historical opportunity[1], through the play to the advantages of tourism electronic commerce to enhance visitors understanding of Fuzhou area, the increase of Fuzhou city tourism competitiveness and improve service quality of Fuzhou city tourism scenic spot. 


\section{The necessity and feasibility of e-commerce application in Fuzhou tourism industry}

\subsection{The necessity of e-commerce application in tourism industry of Fuzhou city}

Although the tourism industry of Fuzhou city is developing rapidly nowadays, its number of tourists and tourism income are still in a relatively backward position in Jiangxi province. With the rapid development of e-commerce in China, more and more tourists learn about the status quo of the scenic spot through the Internet.

As a prefecture-level city with relatively backward economy, Fuzhou city should make full use of media platforms such as Weibo and WeChat to attract eyeballs for publicity and promotion in order to expand the popularity of its scenic spots, despite its abundant tourism resources. Tourists in Fuzhou are generally distributed in the form of individual tourists. Therefore, the Internet has become an important way for tourists in Fuzhou to understand relevant tourism information before traveling [2].

\subsection{The feasibility of e-commerce application in tourism industry in Fuzhou city}

The dependence and density of tourism information is the foundation of modern network information technology developing at an amazing speed in the tourism industry. Tourism enterprises and tourist destinations which cannot be updated and disseminated in time will be in a weak position.

At present, Fuzhou's e-commerce industry has been rapidly developed, and the city now has more than 680 e-commerce enterprises. In 2015, the online trading volume of Fuzhou city was as high as 21 billion yuan. In 2016, the online trading volume of Fuzhou city was still significantly higher than that of 2015, indicating that Fuzhou city has sufficient strength to apply e-commerce to tourism. Fuzhou is rich in tourism resources, and the rapid development of tourism in these years is obvious to all. At the same time, the municipal tourism administration promotes the cooperation with various radio programs through the connection with various provincial and municipal TV stations, and strengthens the publicity of scenic spots. As for the application of e-commerce in the tourism industry of Fuzhou city, I learned that most mainstream tourism websites have links for promotion, consultation and accommodation booking of tourist attractions in Fuzhou.

\section{Analysis on the application status of tourism electronic commerce in Fuzhou city}

\subsection{Fuzhou tourism e-commerce development status}

From an economic perspective, the online trading volume in Fuzhou city reached 21 billion yuan in 2015. In 2016, the online trading volume of Fuzhou city was still significantly higher than that of 2015. According to the statistics of relevant departments, the total tourism revenue was up to 130 million yuan. Tourism revenue during the 2017 Spring Festival holiday was 400 million yuan. From the perspective of industrial layout, Fuzhou city strives to form the industrial development pattern of "one nuclear three circles", including the characteristic tourism circle with Linchuan, Zixi, Jinxi, lean and Lichuan as the main components, and increases the development of four tourism modes of red tourism, cultural tourism, rural tourism and ecological tourism. From the perspective of tourism policy, Fuzhou has comprehensively integrated tourism resources in recent years and designed five featured routes, which are respectively eco-environmental experience tour, rural appreciation tour, religious tour, Linchuan cultural experience tour and red tour. 


\subsection{Analysis of Fuzhou tourism e-commerce market}

Fuzhou has 1 national 4A scenic spot, 3 national 3A scenic spot and 6 provincial scenic spots. Created a total of 38 national and provincial ecological towns, 33 national and provincial ecological village, and owns more than 40 historical cultural relics protection units, the size of the various tourist attractions, indicating that it has very rich tourism resources, and the scale of Fuzhou city tourism played important roles in jiangxi province tourism scale, specific see table 1 below.

Table 1 Tourism revenue of Jiangxi and Fuzhou from 2013 to 2016 (unit: 100 million yuan)

\begin{tabular}{|c|c|c|c|}
\hline year & Fuzhou's tourism revenue & $\begin{array}{c}\text { Jiangxi province's tourism } \\
\text { revenue }\end{array}$ & $\begin{array}{c}\text { Percentage } \\
\text { (\%) }\end{array}$ \\
\hline 2013 & 99.70 & 1896.06 & 5.25 \\
\hline 2014 & 133 & 2649.70 & 5.02 \\
\hline 2015 & 184 & 3637.65 & 5.06 \\
\hline 2016 & 258 & 4993.29 & 5.17 \\
\hline
\end{tabular}

Presently, Fuzhou electronic commerce develops rapidly. In 2015, the online trading volume in Fuzhou city reached 21 billion yuan, of which 900 million yuan was generated during the golden week holiday alone. The online trading volume in 2016 was still significantly higher than that in 2015. During the May Day holiday, the tourism revenue in Fuzhou reached 130 million yuan, up 30 percent year-on-year. Tourism revenue of Fuzhou reached 400 million yuan during the 2017 Spring Festival holiday, up 43 percent year-on-year. This shows that the application of e-commerce in Fuzhou tourism and the market has been basically mature.

\subsection{The application of scenic spots in tourism e-commerce websites in Fuzhou city}

In search of Fuzhou on tuniu website, the navigation bar is divided into four modules: all products, hotel, tickets and travel notes. Under the navigation bar, "money-saving package" is recommended, but only two products are: "Fuzhou fashui forest hot spring" and "jinzhu waterfall ancient". The disadvantage is that there is no room and board recommended links and travel description references in the detail page, and the attractions are very few and very single.

Search Fuzhou on ctrip's official website, the information is relatively complete. The navigation bar is divided into 11 modules: home page, guide, transportation, scenic spot, food, accommodation, shopping, play, travel and local guide. The detailed page of scenic spots includes a brief introduction and comments, nearby scenic spots, group purchase and transportation. Its drawback is the lack of interactive columns, travel mode is not broken down.

In search of tongcheng website in Fuzhou, you can see the navigation bar including hot, scenic spot ticket, wine + scenery package, among which there are 7 popular scenic spots, 6 scenic spot ticket sales and 1 hotel + scenic spot package. The disadvantages of the website are no user comments and travel notes, no distinction between self-driving Tours and group Tours, and fewer attractions.

Search Fuzhou on the donkey mother travel website. The disadvantage of the website is that the "related travel notes" column on the detail page of the scenic spot is 0 , and the navigation bar contains "peripheral tour with group tour", but it lacks the recommendation of related products such as "self-driving tour".

\subsection{The application of third-party e-commerce platform to sell tourism products}

Input the key words in the taobao Tmall "Fuzhou", a total of Fuzhou tourism characteristic hotel to search the relevant products of about 450 items, including sales record of 147 items, sold more than 
10 products have 10 , and the common characteristics of the products is: 1 , its characteristic hotel sales of most of the body of the development of the electronic tourism for some well-known hotel flagship store; 2. Most of the locations are gandong avenue; 3. Most of its products are large beds. After entering the keyword "Fuzhou native product" on Tmall, it can be seen that the hot local product of Fuzhou is nanfeng honey orange, linchuan vegetable stem, nanfeng mud furnace, guangchang lotus root powder, nancheng rice noodle, nanfeng pickled vegetables. In general, the products related to Fuzhou tourism that can be searched on Tmall and taobao are mainly featured hotel sales and local specialty sales.

In Meituan, the city can be located as Fuzhou, where 136 hotels can be searched, among which only 42 hotels have offers, and about 18 hotels with a score of 4.5 or above are priced at 40 to 100 yuan.

\section{A comparative analysis of the development of tourism e-commerce in typical tourist scenic spots inside and outside the city}

The comparative analysis of Fuzhou daguue mountain and jiujiang lushan mountain are both located in jiangxi province and both are beautiful scenic spots. The difference is that the great juehshan mountain in Fuzhou city is rich in animal and plant resources. Lushan mountain, located in jiujiang, jiangxi province, is an advanced unit in the national scenic area and one of the first 5A class tourist areas in China.[3] Therefore, while the lushan scenic spot focuses on beautiful scenery, long history and spectacular waterfalls, the grand jueyan mountain can also follow its practice, highlighting the features and advantages of the grand jueyan mountain, namely, the main type of the lushan scenic spot is rich in flora and fauna and rare, drifting breathtaking and exciting.

The popularity of mt lushan is obviously higher than that of mt daguchi, and a considerable part of tourists prefer to travel freely in $\mathrm{mt}$ daguchi. Therefore, while increasing tourism services and information related to mt daguchi, the website should also launch personalized services according to the characteristics of tourists[4].

A comparative analysis between Fuzhou wang anshi memorial hall and nanyang zhuge wu temple. Both are commemorating historical celebrities, but the nanyang wuhou temple is much older than the Fuzhou wang anshi memorial hall. As the celebrity effect of zhuge liang was higher than that of wang anshi, the tourists in zhuge liang were more widely distributed. Both sites have official websites for commemorating historical celebrities, but nanyang wuhou temple has more detailed sub-pages and is updated faster than the official website of Fuzhou wang anshi memorial hall. Therefore, when expanding the popularity of Fuzhou wang anshi memorial hall, we should actively publicize the history of wang anshi as one of the "eight masters of tang and song", improve its official website and update it in time, and at the same time improve and enrich relevant content on famous tourism websites such as ctrip and tongcheng.

\section{Problems in the development of tourism e-commerce in Fuzhou city}

a) Few websites and low overall development level: Most tourism websites in Fuzhou are short of humanized services, and their views on tourism still remain on the traditional basis. They cannot timely update and release tourism information and products, and cannot view problems from the perspective of tourists.

b) Low transaction security: While studying Fuzhou tourism e-commerce, we found that most consumers are reluctant to use e-commerce shopping model for shopping, because they are afraid of personal information leakage[5]. Therefore, many consumers are reluctant to consume online commodities, including tourist commodities, for fear of the security of online transactions. 
c) The tourism e-commerce website is less professional: Although many tourism websites in Fuzhou provide accommodation booking and ticket booking for scenic spots, they still adopt the method of "online ordering and offline settlement", which still cannot realize the perfect application of e-commerce to tourism[6].

d) Single website services: Single website services. At present, all major tourism websites are limited to providing information services and booking services for scenic spots in Fuzhou, without providing special services for tourism positioning in Fuzhou and failing to highlight the characteristics of tourism products in Fuzhou. Most tourism websites describe the Fuzhou scenic spot and offer similar service modes to other similar scenic spots.

e) Deficiencies in network marketing and promotion: There is no effective integration of marketing methods such as video, weibo, community, travel, etc., nor integration of search engine and promotion of mobile APP. The advantages of online marketing are not fully demonstrated.

\section{Conclusions}

In view of the development of Fuzhou tourism e-commerce, its primary task is to perfect its tourism website. Only by optimizing the design of the tourism website can its advantages be effectively displayed. In order to improve the entrance speed of the website and meet the current requirements of big data for tourists, it is necessary for the website to link all scenic spots in Fuzhou to the leading page. You can use multimedia tools to edit the web content to enrich the content of the relevant web pages of Fuzhou scenic spot, such as food, travel, accommodation, travel, shopping, entertainment, etc., so as to attract the attention of potential tourists. Perfect the website's e-commerce function.

Tourism industry in Fuzhou is also a pillar industry in Fuzhou. Relevant government departments should take the lead in providing appropriate policies and financial assistance to relevant enterprises, issuing relevant laws and regulations to regulate their tourism e-commerce websites, and effectively improving the existing problems of their tourism e-commerce.

Fuzhou city is a prefecture-level city with a large number of tourism resources. The common goal of Fuzhou tourism enterprises is to build it into a tourism region with local characteristics, making it stand out among numerous tourism regions.

Tourism departments and enterprises in Fuzhou should pay more attention to online marketing, realizing that compared with traditional marketing, online marketing has lower cost and wider range of communication, and conducting online marketing can make statistics on its customers and potential customers. In order to carry out network marketing, Fuzhou scenic spot must strengthen the integration of microblog, WeChat, video and other marketing aspects, make full use of existing network resources and develop potential network resources, so as to effectively reduce the cost of network marketing, enhance the ability of "publicity" and "marketing potential", and expand the scale of publicity.

\section{Acknowledgments}

The project is funded by the humanities and social sciences research and planning fund of the ministry of education (14YJA910004), the natural science foundation of jiangsu province (BK20151481) and the national social science foundation (16BTJ019).

\section{References}

[1] Lin Han. Exploration of building yangshuo rural tourism website [J]. Journal of guilin university of tourism, 2004, pp.82-86. 
[2] W.X. Xue. Construction of e-commerce website [M]. Beijing: mechanical industry press, 2007.

[3] Xiaomei He, Lin Zheng, Yanzhen Wang, et al. Tourism image research on lushan mountain [J]. Economic geography, 2011, 31(3):523-528.

[4] CF Chen. Identifying significant factors influencing consumer trust in an online travel site [J]. Journal of Information Technology \& Tourism, 2006, pp.197-214.

[5] Lei Wang. Online payment and settlement [M]. Hangzhou: zhejiang university press, 2010.

[6] Weiyi Yuan. Research on the development of China's tourism e-commerce based on the O2O model [J]. China business theory, 2015, pp.56-58. 